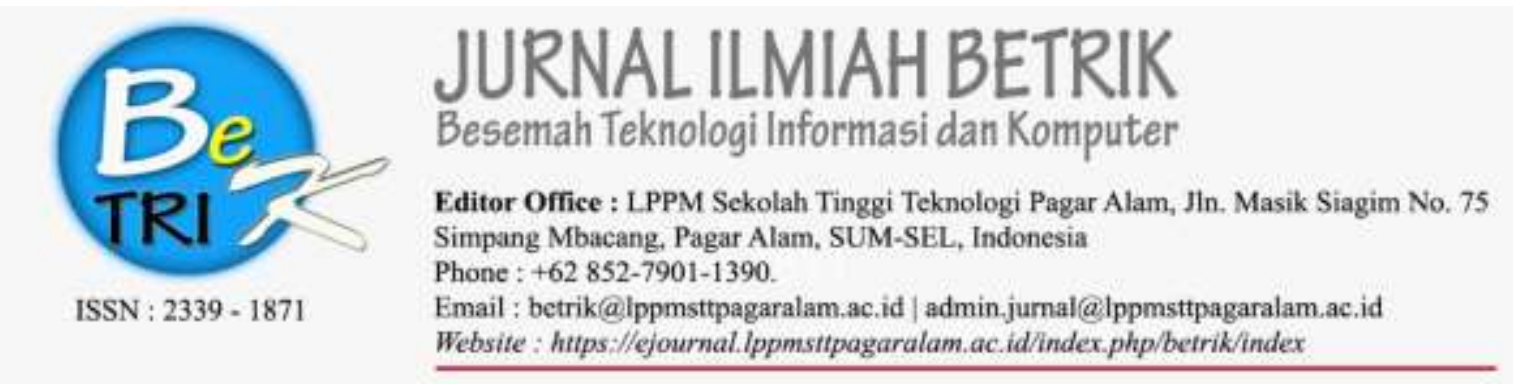

\title{
EVALUASI WEBSITE PEMERINTAH KOTA PRABUMULIH MELALUI PENDEKATAN WEBSITE USABILITY EVALUATION (WEBUSE)
}

\author{
Nur Aini $\mathbf{H}^{\mathbf{1}}$, Rabin Ibnu Zainal ${ }^{2}$, Afriyudi ${ }^{3}$ \\ Program Magister Teknik Informatika Universitas Bina Darma \\ Jl. A. Yani No.3, Palembang 30264, Indonesia \\ Sur-el :ainihutagalung@yahoo.com
}

\begin{abstract}
Abstrak: Kemajuan teknologi informasi dan komunikasi berperan penting pada pelaksanaan $e$ government. Tujuannya adalah agar hubungan-hubungan tata Pemerintahan (governance) yang melibatkan Pemerintah, swasta dan masyarakat dapat tercipta sedemikian rupa sehingga lebih efektif, efisien, produktif dan responsif. Kota Prabumulih merupakan salah satu Daerah Otonom yang ada di Indonesia yang telah mengimplementasikan e-government melalui website, dengan alamat www.prabumulih.go.id. Penelitian ini mengacu pada pendekatan Website Usability Evaluation (WEBUSE) untuk mengevaluasi usability pada website Pemerintah Kota Prabumulih dengan dimensi Content, OrganisationandReadibility, Navigationand Link, User Interface Design serta Performanceand Effeciveness. Website Usability Evaluation (WEBUSE) berfokus pada pengembangan sistem evaluasi usability berbasis web dengan pendekatan tindakan subyektif yang melibatkan partisipasi dari pengguna untuk memberikan penilaian pada sebuah website. Pengembangan pendekatan Website Usability Evaluation (WEBUSE) sebagai standar pengukuran usability, dengan metode evaluasi kuisioner berbasis web yang memungkinkan pengguna untuk menilai usability dari website yang akan dievaluasi Tujuan dari penelitian ini adalah untuk mengetahui tingkat usability dari website Pemerintah Kota Prabumulih agar Pemerintah Kota Prabumulih dapat memberikan pelayanan yang optimal kepada pengguna.
\end{abstract}

Kunci Utama: e-goverment, website usability evaluation

\begin{abstract}
The progress of information and communication technology plays an important role in the implementation of e-government. The aim is that governance relations involving the Government, the private sector and the community can be created in such a way that they are more effective, efficient, productive and responsive. Prabumulih City is one of the Autonomous Regions in Indonesia that has implemented e-government through the website, with the address www.prabumulih.go.id. This study refers to the Website Usability Evaluation (WEBUSE) approach to evaluate usability on the Prabumulih City Government website with the dimensions of Content, Organization and Readibility, Navigation and Link, User Interface Design and Performance and Efficiency. Website Usability Evaluation (WEBUSE) focuses on developing a web-based usability evaluation system with a subjective action approach that involves the participation of users to provide an assessment on a website. The development of the Website Usability Evaluation (WEBUSE) approach as a standard usability measurement, with a webbased questionnaire evaluation method that allows users to assess the usability of the website to be evaluated The purpose of this study is to determine the usability level of the Prabumulih City Government website so that Prabumulih City Government can provide optimal service to users.
\end{abstract}

Keywords : e-goverment, website usability evaluation 


\section{PENDAHULUAN}

Dewasa ini kemajuan teknologi informasi dan komunikasi memberikan banyak manfaat kepada manusia. Kemajuan ini terjadi pada berbagai bidang, mulai dari pendidikan, militer, ekonomi, kedokteran hingga pemerintahan. Pada bidang pemerintahan, manfaat yang diperoleh pengguna, baik itu pengguna secara individu, kelompok, organisasi, perusahaan maupun instansi adalah dengan adanya layanan $e$ government. e-government berdasarkan The World Bank Group (2001) dalam Kumorotomo (2009) adalah "E-Government refers to the use by government agencies of information technologies (such as Wide Area Network, the internet, and mobile computing) that have ability to transform relations with citizens, business and other arms of government". Dari definisi tersebut dapat dilihat bahwa e-government merujuk pada penggunaan teknologi informasi pada Lembaga Pemerintah atau Lembaga Publik. Tujuannya adalah agar hubungan-hubungan tata Pemerintahan (governance) yang melibatkan Pemerintah, swasta dan masyarakat dapat tercipta sedemikian rupa sehingga lebih efektif, efisien, produktif dan responsif. Konsep $e$ government mengacu bukan hanya pada pemakaian teknologinya namun juga keharusan pada prinsip bahwa pemanfaatan teknologi akan membuat sistem penentuan kebijakan dan pelayanan publik menjadi lebih baik serta dan membuat Pemerintah lebih bertanggung jawab kepada masyarakat.

Kota Prabumulih merupakan salah satu Daerah Otonom yang ada di Indonesia yang telah mengimplementasikan e-government melalui website, dengan alamat www.prabumulih.go.id. Mengingat keberadaannya yang telah cukup lama maka diperlukan evaluasi guna memaksimalkan fungsinya. Berdasarkan Instruksi Presiden Nomor 3 Tahun 2003 yang menjelaskan bahwa untuk mencapai tata kelola e-government yang baik perlu adanya evaluasi yang kontinyu.

Menurut Karat (1994), usability merupakan salah satu aturan dalam penerapan User Centered Design (UCD). User Centered Design (UCD) merupakan paradigma baru dalam pengembangan sistem berbasis web. User Centered Design (UCD) adalah tentang partisipasi dan pengalaman manusia dalam proses perancangan danpengembangan berbasis web. Maka dari itu, partisipasi dari pengguna sangatlah dibutuhkan dalam proses pengembangan untuk menciptakan sistem informasi yang lebih baik.

Usability adalah salah satu barometer yang dapat menggambarkan kualitas sebuah sistem dari sudut pandangan manusia yang menggunakannya dimanapencapaian usability dalam sebuah website memerlukan kombinasi dari perencanaan dalam memahami konteks penggunaan sistem sebagi dasar untuk mengidentifikasikan dan mengevaluasi sistem melalui pengujian pengguna (J Neilsen,1994). Untuk mengetahui suatu sistem dapat digunakan oleh pengguna secara efektivitas, efisiensi dan kepuasan adalah dengan melakukan evaluasi website dari aspek usability (Bevan,2009).

Website Usability Evaluation (WEBUSE) berfokus pada pengembangan sistem evaluasi usability berbasis web dengan pendekatan 
tindakan subyektif yang melibatkan partisipasi dari pengguna untuk memberikan penilaian pada sebuah website. Pengembangan pendekatan WEBUSE sebagai standar pengukuran usability, dengan metode evaluasi kuisioner berbasis web yang memungkinkan pengguna untuk menilai usability dari website yang akan dievaluasi (Chiew dan Salim, 2003). Penelitian ini mengacu pada pendekatan WEBUSE untuk mengevaluasi usability pada website Pemerintah Kota Prabumulih dengan dimensi Content, Organisation andReadibility, Navigation and Link, User Interface Design serta Performance and Effeciveness.

\section{METODE PENELITIAN}

Penelitian ini menggunakan metode tinjauan literatur sebagai metode utama. Sebagai tujuan dari penelitian ini adalah untuk mengembangkan konseptualisasi lebih dalam dan lebih jelas tentang website usability, sebuah literatur pustaka dari usability dengan sudut pandang akademis dan praktisi serta literatur dari sudut pandang teknis, pandangan sosial dan proses IS telah dilakukan. Sebuah metode literatur pustaka sangat cocok digunakan untuk menciptakan dasar yang kuat untuk memajukan pengetahuan dan teori pembangunan (Zaphiris, P., \& Kurniawan, S, 2006) Menurut P.D. Leedy (1997, hal. 71)menerangkan bahwa suatu tinjauan pustaka mempunyai kegunaan untuk: (1) mengungkapkan penelitian-penelitian yang serupa dengan penelitian yang (akan) kita lakukan; dalam hal ini, diperlihatkan pula cara penelitian-penelitian tersebut menjawab permasalahan dan merancang metode penelitiannya; (2) membantu memberi gambaran tentang metoda dan teknik yang dipakai dalam penelitian yang mempunyai permasalahan serupa atau mirip penelitian yang kita hadapi; (3) mengungkapkan sumber-sumber data (atau judul-judul pustaka yang berkaitan) yang mungkin belum kita ketahui sebelumnya; (4) mengenal peneliti-peneliti yang karyanya penting dalam permasalahan yang kita hadapi (yang mungkin dapat dijadikan nara sumber atau dapat ditelusuri karya-karya tulisnya yang lain yang mungkin terkait); (5) memperlihatkan kedudukan penelitian yang (akan) kita lakukan dalam sejarah perkembangan dan konteks ilmu pengetahuan atau teori tempat penelitian ini berada; (6) menungkapkan ide-ide dan pendekatan-pendekatan yang mungkin belum kita kenal sebelumya; (7) membuktikan keaslian penelitian (bahwa penelitian yang kita lakukan berbeda dengan penelitian-penelitian sebelumnya) dan (8) mampu menambah percaya diri kita pada topik yang kita pilih karena telah ada pihakpihak lain yang sebelumnya juga tertarik pada topik tersebut dan mereka telah mencurahkan tenaga, waktu dan biaya untuk meneliti topik tersebut.

Website usability adalah suatu indikator keberhasilan sebuah website dalam berinteraksi dengan pengguna dalam melaksanakan tugas tertentu dengan mudah (Al-Badi \& Meyhew, 2011) Ukuran keberhasilan dari website usability dilihat dari seberapa baik sebuah website dalam memberikan layanan kualitas kepada pengguna, mengurangi kemungkinan kesalahan pada sistem, memudahkan proses pembelajaran website dan penggunaan secara efisien sehingga pengguna merasa puas dengan website tersebut. Untuk dapat mengetahui 
kualitas website dalam berinteraksi dengan pengguna adalah dengan cara melalukan evaluasi website dari aspek usability (Pressman,2005).

WEBUSE(Website Usability Evaluation) merupakan suatu kuesioner yang dikembangkan dari empat buah usability evaluation tool, yaitu WAMMI, WebSAT, Bobby, dan Protocol Analysis untuk mengevaluasi usability dari sebuah website. Kuesioner ini terdiri dari 24 pertanyaan dengan lima opsi jawaban yang terbagi dalam empat dimensi, yaitu :

\section{Content, organization and readability}

Content yang baik adalah content yang mudah dipahami oleh pengguna, jelas, dan terorganisir dengan baik. Website yang terorganisir dengan baik dapat memberikan pemahaman yang cepat bagi pengguna menurut Leavitt dan Shneiderman (Marcus, 2011). Sedangkan, readability sebuah website diukur melalui apakah sistem berfungsi dengan benar dan memberikan informasi yang akurat (Baltzan dan Phillips, 2009).

\section{Navigation and link}

Metode yang digunakan untuk mencari dan mengakses informasi dalam situs web secara efektif dan efisien untuk membantu pengguna website disebut dengan Navigation. Sedangkan, links berfungsi menghubungkan pengguna dengan cara memilih dan mengklik links pada halaman hypertext (homepage), yang menyebabkan terbukanya halaman baru. linksyang baik harus menggunakan teks daripada grafis sehingga mudah dipahami oleh pengguna menurut Leavitt dan Shneiderman (Marcus, 2011).

\section{Desain user interface}

User interface design sebuah metode dan prosedur yang membutuhkan pertimbangan dengan baik saat merancang dan mengembangkan website. Hal yang penting dalam merancang userinterface design diantaranya menetapkan tujuan, menentukan pengguna dan menyediakan content yang bermanfaat. Untuk memastikan hasil yang terbaik perlu mempertimbangkan berbagai isuisu user interface design dan unjuk kerja yang baik bagi pengguna menurut Leavitt dan Shneiderman (Marcus, 2011).

\section{Performance and effectiveness}

Performance website dapat diukur dengan cara seberapa cepat suatu website melakukan proses atau transaksi tertentu sehingga menghasilkan kinerja pengguna yang cepat dan efisien (Baltzan dan Phillips, 2009). Sedangkan, effectiveness merupakan keberhasilan sebuah website menghasilkan informasi yang tepat bagi pengguna menurut Leavitt dan Shneiderman (Marcus, 2011).

\section{HASILDANANALISIS}

\section{Tabel 1. Referensi Penulis}

Berikut ini adalah Beberapa Jurnal yang menjadi referensi penulis, yaitu :

\begin{tabular}{|c|c|c|c|c|c|c|c|c|c|c|}
\hline \multirow[b]{2}{*}{$\begin{array}{l}\mathbf{N} \\
\mathbf{o}\end{array}$} & \multirow[b]{2}{*}{$\begin{array}{c}\text { Penel } \\
\text { iti }\end{array}$} & \multicolumn{9}{|c|}{ Faktor Usability (hasil) } \\
\hline & & $\begin{array}{l}\text { Eff } \\
\text { ecti } \\
\text { ven } \\
\text { ess }\end{array}$ & $\begin{array}{c}\text { Le } \\
a r n \\
a \\
b i l i \\
t y\end{array}$ & $\begin{array}{c}\text { Me } \\
\text { mo } \\
\text { rab } \\
\text { ilit } \\
y\end{array}$ & $\begin{array}{l}E \\
r \\
r \\
o \\
r\end{array}$ & $\begin{array}{c}\text { Sat } \\
\text { isf } \\
a c \\
\text { tio } \\
n\end{array}$ & $\begin{array}{c}\text { Content } \\
\text {, } \\
\text { organiz } \\
\text { ation } \\
\text { and } \\
\text { readabil } \\
\text { ity }\end{array}$ & $\begin{array}{c}\text { Navig } \\
\text { ati } \\
\text { on } \\
\text { and } \\
\text { link }\end{array}$ & $\begin{array}{c}\text { Desai } \\
\quad n \\
\text { user } \\
\text { interf } \\
\text { ace }\end{array}$ & $\begin{array}{c}\text { Perfo } \\
\text { rman } \\
\text { ce } \\
\text { and } \\
\text { effect } \\
\text { ivene } \\
\text { ss } \\
\end{array}$ \\
\hline 1 & $\begin{array}{l}\text { Nita } \\
\text { Rosa } \\
\text { Damay } \\
\text { anti [8] }\end{array}$ & $\mathrm{x}$ & $\mathrm{x}$ & $\mathrm{x}$ & $\mathrm{x}$ & $\mathrm{x}$ & $\mathrm{x}$ & & & \\
\hline 2 & $\begin{array}{l}\text { D. } \\
\text { Jumeno } \\
\text { dan D. } \\
\text { H. Putri } \\
\text { [9] }\end{array}$ & & $\mathrm{x}$ & $\mathrm{x}$ & $\mathrm{x}$ & & $\mathrm{x}$ & $\mathrm{x}$ & & $\mathrm{x}$ \\
\hline 3 & $\begin{array}{l}\text { Amalia } \\
\text { Mardhi } \\
\text { a Ersa } \\
{[10]}\end{array}$ & & $\mathrm{x}$ & & & $\mathrm{x}$ & & $\mathrm{x}$ & $\mathrm{x}$ & $\mathrm{x}$ \\
\hline
\end{tabular}




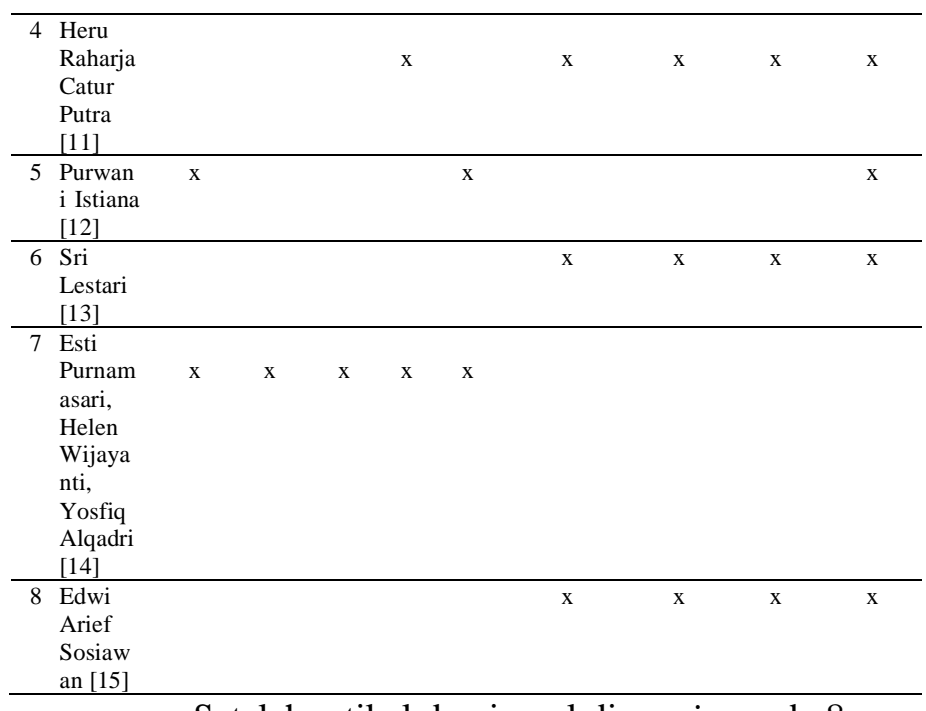

Setelah artikel dan jurnal di re-view, ada 8

jurnal yang revelevan dengan penelitian ini maka peneliti dapat menarik kesimpulan dimensi usability yang paling banyak adalah Performance and effectivenesdalam mengevaluasi website. Hal ini dikarenakan bahwa dimensi Performance and effectiveness yang mampu memenuhi 6 dari 8 penelitian. Hal ini menunjukan kalau Performance and effectiveness merupakan dimensi pertama yang diperhatikan oleh pengguna. Sedengkan yang kedua terdapat di dimensi Content, organization and readability dan Navigati on and linkdikarnakan berpengaruh dalam membantu pengguna dalam memanfaatkan website. Sedangkan Effectiveness , Learnability, Memorability, Error, Satisfaction dan Desain user interface merupakan dimensi berikutnya yang mempengaruhi usability suatu website.

\section{KESIMPULAN}

Dari invetigasi ini maka dapat ditarik kesimpulan bahwa Performance and effectiveness merupakan dimensi usability yang berperan penting dalam sebuah webaite, tentu saja hal ini dapat memacu instansi baik itu instansi pendidikan maupun pemerintahan untu dapat lebih mengembangkan website yang dimiliki dengan menjadikan Performance and effectiveness sebagai tolak ukur yang pertama. Dengan kata lain semakin tinggi tingkat Performance and effectiveness maka semakin baik sebuah website. Adapun saran yang penulis miliki untuk melanjutkan penelitian ini agar bisa memperluas populasi yang ada dengan menggunkan metodologi penelitian yang sesuai dengan penelitian yang akan dilanjutkan.

\section{DAFTAR RUJUKAN}

\section{Daftar Pustaka menggunakan APA Style}

Referensi dari buku:

Karat, C-M. (1994). A Business Case Approach to Usability Cost Justification. In Bias, R., Mayhew, D. Cost-Justifying Usability. Academic Press, pp 45-70.

Chiew and Salim (2003). WEBUSE: Website Usability Evaluation Tool. Malaysia.

J. Nielsen, Usability engineering: Elsevier, 1994.

Baltzan, Paige dan Amy Philips. (2009). Essentials of Business Driven Information Systems, New York.

Marcus, Aaron. (2011). Design, User Experience and Usability Part 1 and Part 2. Orlando: Springer.

Pressman, S.R., (2005) Software Engineering: A Practitioner's Approach International Edition, McGraw-Hill.

Zaphiris, P., \& Kurniawan, S. (2006). Human Computer Interaction Research in Web Design Evaluation. UK: Idea Group Publishing. 
P.D. Leedy (1997) Practical Researh :

Planning and Design.

Lestari, Sri. E-Catalog Public Facilities Development With the Additional Website Usability Evaluation. 2013.

Referensi dari internet

Kumorotomo (2009). Implikasi Teknologi Informasi dan Internet Terhadap Pendidikan, Bisnis dan

Pemerintahan. Pusat Penelitian Antar Univeristas bidang Mikroelektronika (PPAUME), Institut Teknologi Bandung.

Bevan, N. (2009, August). What is the difference between the purpose of usability and user experience evaluation methods. In Proceedings of the Workshop UXEM (Vol. 9).

A. H. Al-Badi, A. O. Al Majeeni, P. J. Mayhew, and A. S. Al- Rashdi "Improving Website Ranking through Search Engine Optimization," Journal of Internet and eBusiness Studies, vol. 2011, pp. 1-11, Jan. 2011.

Rosa Damayanti, Nita. Evaluasi Website Pascasarjana Magister Teknik Informatika Bina Darma Palembang Menggunakan Usability Testing. Universitas Bina Darma Palembang.2012.

D. Jumeno dan D. H. Putri. Analisis Usability Website Universitas Andalas. Universitas Andalas Padang, 2010

Amalia Mardhia Ersa. Usability Evaluation Website E-Goverment : Layanan Aspirasi dan Pengaduan Online (LAPOR!): Perbandingan Antara Existing Product dan Development Product. Uniersitas Indonesia. 2015.

Heru Raharja Catur Putra. Analisis Usability Website Repository Perpustakaan Iinstitit Teknologi Sepuluh Nopember Surabaya. 2014.

Purwani Istiana. Evaluasi Usability Situs Web Perpustakaan UGM. Vol. 13 No. 3 Desember 2011.

Esti Purnamasari, Helen Wijayanti, Yosfiq Alqadri. Evaluasi Website JobDBTM Dengan Metode Usability Heuristic. 2012. Edwi Arief Sosiawan. Evaluasi Implementasi EGoverment Pada Situs Web Pemerintah Daerah Indonesia : Perspektif Content Dan Manajemen. 2012 